\title{
Substrate specificity of protein kinase C inhibitors
}

\author{
Differential substrate specificity could be exploited
}

In the August issue of TiPS, Epand and Lester analysed the effect of the physicochemical properties of the membrane on protein kinase $\mathrm{C}$ activity. In addition to those substrates discussed that require the presence of $\mathrm{Ca} 2+$ and phospholipids, other substrates can be phosphorylated in the absence of these activators. It is possible that this differential substrate requirement could be exploited pharmacologically.

Three types of substrate have been characterized according to the nature of the activators (Ca2+, diacylglycerol and phospholipids) required for the phosphotransferase activity.

- Substrates requiring $\mathrm{Ca} 2+$ and lipids which form a ternary complex with protein kinase $\mathrm{C}$ prior to phosphorylation, e.g. histone $\mathrm{H} 1$, troponin $\mathrm{I}$, and $>80 \%$ of the cytosolic proteins from rat liver that are phosphoryiated by protein kinase $\mathrm{C}$.

- Substrates independent of $\mathrm{Ca} 2+$ but dependent on phospholipids, such as myelin basic protein and several lysine, serine or arginine copolymers.

- Substrates independent of both $\mathrm{Ca} 2+$ and phospholipids, e.g. protamine and peptides containing the substrate sequence derived from protamine.

In the latter case, direct interaction of protein kinase $C$ with serine residues between extended basic sequences in protamine is sufficient to induce structural changes that unmask the catalytic site of protein kinase C.

The complex reaction catalysed by protein kinase $C$ offers the possibility of the development of a broad spectrum of inhibitors that may bind either to the catalytic site (e.g. isoquinoline, $\mathrm{H} 7$, staurosporine or K252 and pseudosubstrate peptides), or to the regulatory domain (e.g. sphingosine, phospholipid interacting drugs and aminoacridines). Combined with the different substrate specificities elicited by protein kinase $C$ phosphorylation of physiological substrates, these chemically diverse agents may allow a useful definition of sets of inhibitors with potential pharmacological interests. For example, in the experimental model of twostep carcinogen-induced skin tumour promotion, staurosporine inhibited tumour growth but failed to prevent other phorbol diester-induced effects, such as oedema formation or epidermal hyperplasia, that were inhibited by quercetine; these differential effects were attributed to substrate-dependent specificity for staurosporine inhibition of protein kinase C. Similarly in cultured epidermal cells stimulated with phorbol diesters, $\mathrm{H} 7$ inhibited the rise in omithine decarboxylase activity, but failed to prevent the downregulation of EGF receptor, a process in which protein kinase $\mathrm{C}$ is involved. 